\title{
The Global World: New Educational Models Of Intercultural Communication
}

\author{
Natalia A. Orekhovskaya ${ }^{1 *}$, and Elena A. Yalozina ${ }^{1}$ \\ ${ }^{1}$ Financial University under the Government of the Russian Federation, Department of Sociology, \\ History and Philosophy, Moscow, Russia
}

\begin{abstract}
The relevance of the study is determined by the increasing importance of intercultural interaction in a globalizing world. These processes need new educational models and innovative methods for implementation in the educational process. The objective of the article is to analyze the theoretical and methodological experience and find innovative educational methods in the study of intercultural communication. The methods used by the authors are the analysis and synthesis of theoretical literature. Besides, the comparative and typological analyses of pedagogical experience in the field of building educational models of intercultural communication are carried out. The result of the work is the identification of specific innovative approaches to the study of the interdisciplinary nature of intercultural communication. The conclusion drawn by the authors is that the basis of any educational model should be tolerance and respect for the carriers of another culture.
\end{abstract}

\section{Introduction}

The global cultural climate is transforming at a rapid pace. The situation requires organizing behaviour in multicultural environments that contribute to the prevention of intercultural conflicts in society. It must form a willingness to find the best ways to overcome the unpredictable situations arising from the clash of cultures. Communication and stability are extremely controversial phenomena. However, in the modern multicultural community, there is an inextricable relationship between them [1]. The dynamics of their interaction demonstrates new opportunities and limitations.

The objective of the study is to find innovative educational methods in the study of intercultural communication. To achieve this goal, we set research tasks, the main of which are, firstly, to analyze the theoretical and methodological experience, and secondly, to identify models on which the interaction of cultures is based. The orientation of modern postindustrial civilization to production and comprehensive development of science is an unquestionable unifying factor not only for the multitude of industrial but for traditional cultural opportunities as well. However, the specificity and features of the new information reality cannot be fixed yet [2]. One can only assert for sure the enormous importance of technical progress, both in the era of industrialization and at the present stage of the socio-

\footnotetext{
*Corresponding author: naorehovskaya@,fa.ru
} 
cultural development of society. In the modern realities of intercultural interaction, it even changes spiritual values [3]. Formulating the research hypothesis, we assume that in the process of transition of a society to the post-industrial state, spiritual values become dominant.

In all spheres of human activity, intralinguistic and interlinguistic communication are compared. The importance of interaction between different cultures is increasing. The modern world is undergoing globalization [4]. These processes that are occurring in society today determine the relevance of studying intercultural communication.

An updated theory of understanding of intercultural communication is required, and methods for its study should be developed and optimized. Through the prism of the anthropocentric superparadigm, the prerequisites for the study of enlarged objects of integration in a "broad extra-linguistic context" are created [5].

Western and Russian schools of intercultural communication [6, 7] say that the integration of the achievements of both schools is real. They have a strong heuristic potential and correspond to the spirit of communication between cultures, which is the way to move to the dialectical stage of development of this phenomenon.

The theory of intercultural communication is not sufficiently developed, which negatively affects the implementation of the profound adaptation of the individual to the existing multicultural space, as well as does not allow the effective use of internal resources [8]. Thus, in conditions of cultural instability, it is impossible to achieve the harmonization of communication and the intended result. The current picture shows that the era oriented to material and technical values has been exhausted. It is necessary to move from strict economic determinism to spiritual values - the instrumental mind needs to be replaced by a mind that promotes "communicative interactions" of an individual with nature, a person with a person, and a person with a cultural sphere [9]. The development of society is changing under the influence of a rapid cultural movement. Economic growth no longer serves as a dominant reference point [10].

The methodology of this work is based on philosophical and cultural approaches adopted by Russian and foreign scientists. They are distinguished by their attention to the process of communication, as well as to its conditioning by socio-cultural experience, knowledge, ideas, concepts, norms, and values that have historically developed in each culture, particularly in the culture of its native speakers. There were also used the analysis and synthesis of theoretical literature, comparative, typological, and semantic-pragmatic analysis of fragments of the logical conclusion.

Due to the interdisciplinary nature of intercultural interaction, specific approaches may be required to investigate this phenomenon within each scientific branch [11]. At present, three methodological approaches have been formed: explanatory, critical, and functional.

\section{Results}

By studying the process of intercultural communication through theory, we can identify the models on which cultural interaction is built. There are adaptation and hermeneutic models. In the first case, we assume communication between representatives of different cultures during gradual adaptation to communicative features of the opposite side. In the second case, intercultural communication is considered as a reinterpretation of a person's cultural experience, aimed at analyzing and understanding another culture.

To build an innovative model of intercultural communication, specific tools are needed [12]. They are based on education and training.

The task of education is to accumulate knowledge about the culture of another nation, its ethnic community, etc. [13] Starting to communicate with a foreigner, it is necessary to get 
acquainted with the history of their nation, geography of their country, and traditions and customs of its inhabitants.

The training practically prepares one for direct interaction with members of other cultural groups. The main objectives of intercultural training, according to G. Triandis, are:

- Introduction to cultural differences at the level of interpersonal relations. Here the situations, which have the two different cultures, are reproduced.

- The creation of opportunities to transfer acquired knowledge to new situations. It is achieved by acquaintance with the most characteristic features of another culture [14].

Often common cultural training is used - programs focused on making a person realize that they represent another culture or group. Individuals are trained to recognize the value of their own culture and to analyze cross-cultural differences. As a result, they develop the skills to penetrate cultural differences, which increases the effectiveness of interaction.

\section{Discussion}

In pedagogical practice, we can distinguish several approaches to training structuring. For example, C. Rogers conducts classes with real intercultural contacts [15]. Similar training sessions have been conducted in Northern Ireland and South Africa among members of local conflict groups. However, such training does not always lead to a goal - students are hampered by powerful ethnocentrism and their strong prejudices.

The method of cultural assimilators, which is practiced by psychologists of the University of Illinois, is also quite actively used [16]. This method is based on the principle of teaching the listener to look at the situation from the point of view of a representative of another culture and to understand their vision of the world around them. This technique allows increasing intercultural sensitivity [17].

In modern pedagogical practices, the method of attributive training is used, focusing on how representatives of different ethnicities and cultures interpret the behavioural causes and results of the opposite side. The task is extremely important because the main problem that arises in the process of intercultural communication is people's misunderstanding of the reasons for each other's behavioural reactions, from which they make erroneous conclusions. Through attributive training, it is possible to achieve maximum precision from the individual's expectations regarding the possible behaviour of a member of another culture. This contributes to the mastery of isomorphic attributions - explanations that are characteristic of a culture with which a person will have to interact [18].

The cultural assimilator is a method of cognitive orientation. It is often used for training programs [19]. A group of students discusses and compares the results of each other and participates in role-playing games with cultural assimilator situations. Then it becomes a basic method in attributive training because the task of students is to determine the isomorphic attribution, i.e., the interpretation of intercultural interaction that will coincide with the point of view of another group.

\section{Conclusion}

The above-mentioned methods allow comparing two or more cultures in practice, focusing on both the general difficulties inherent in intercultural communication and the particular cases of communication. Using them in the teaching of intercultural communication allows preparing people from different cultures to establish effective contacts and teaches people to understand their communicative partners in interaction, which leads to the desired results and goals [20]. 
The problem of intercultural communication is complex and involves many aspects. Various fields of knowledge converge on it, so there is no doubt that further studies are needed $[21,22]$. There are several reasons why intercultural differences should be studied. First of all, such knowledge provides a clear understanding of the features of one's own culture. The effectiveness of interaction with representatives of other cultures increases. An effective mechanism for relieving interethnic tension appears. This knowledge will help to avoid ethnic conflicts. By researching the cultures of other peoples, one learns tolerance and respect.

The opportunities for intercultural communication are greatly enhanced through audiovisual technologies. Thanks to them, an increasing number of representatives of different ethnic groups are included in the process of cultural communication. By getting acquainted with the practices of other cultures, a person comes to the idea of the undeniable uniqueness of their culture. Being elevated to the absolute, this idea can give unexpected reactions and behavioural scenarios, which are not always positive.

Channels of intercultural communication in post-industrial society are changing. Audiovisual technologies are expanding their diversity. New communication trends are emerging that transform traditional cultural space, which, in the era of globalization, is transformed into an active participant of intercultural interactions. For example, the development of information technologies is transforming the education institute.

Communication must cope with its main mission - to build understanding between cultural carriers and to foster tolerance of the individual characteristics of each of them. It is necessary to develop multiculturalism in human thinking. The primary ideals of modern cultural information space are spirituality, morality, cultural creativity, and personal growth. They will allow humanity to cope with the difficulties that arise in the process of changing the cultural and communicative field.

The obligatory attribute inherent in any significant socio-cultural interaction, whether it is the contact between individuals or the dialogues of civilizations and cultures, is moral culture. It is a factor that characterizes both the interaction itself and its results, defining the code, form, and norms of intragroup communication.

In practice, moral culture affects the moral creative power of a person. By this force we understand self-creation and regulation of relations in society based on moral priorities existing in concrete cultural and historical realities. Cultures are enriched with value content and develop with maximum productivity in the process of dialogue.

\section{References}

1. I.G. Belyakova, Kultura i tsivilizatsiya 9(4)A, 138-147 (2019)

2. R. Inglehart, Cultural Evolution: People's Motivations are Changing, and Reshaping the World (Mysl, Moscow, 2018)

3. Yu.V. Zinkina, E.V. Slinko, D.A. Bykanova, A.V. Korotaev, Zhurnal sotsiologii i sotsialnoy antropologii 21(1), 44-72 (2018)

4. R. Inglehart, C. Welzel, Modernization, Cultural Change, and Democracy (Novoye izdatelstvo, Moscow, 2011)

5. N.D. Arutyunova, Language and the world of man (Yazyki russkoy kultury, Moscow, 1999)

6. T.M. Permyakova, Intercultural communication in the light of the theory of discourse: monograph (Izd-vo Perm. un-ta, Perm, 2007)

7. N. Koljada, S. Kowalskaia, A. Melkonyan, XLinguae 12(2), 28-39 (2019)

8. A. Kayumov, N. Muginova, Y. Leonova, V. Sarayeva, XLinguae 11(1), 72-79 (2018) 
9. J. Habermas, The theory of communicative action. Sovremennaya zapadnaya teoreticheskaya sotsiologiya (Nauka, Moscow, 1992)

10. R. Inglehart, Culture Shift in Advanced Industrial Society (Academia, Moscow, 1999)

11. R. Valeeva, A. Valeeva, Procedia - Social and Behavioral Sciences 23721, 1564-1571 (2017)

12. I. Lianaki-Dedouli, J. Plouin, Futures 94, 45-58 (2017)

13. H. Heizmann, A. Fee, S. J. Gray, Journal of International Managemen 24(1) 16-32, (2018).

14. H. Triandis, Intercultural Education and Training. Understanding the USA. A CrossCultural Perspective (Tuebingen, 1989).

15. C. Rogers, Counseling and Psychotherapy (Izdatelstvo Instituta psikhoterapii, Moscow, 2006)

16. T.G. Stefanenko, E.I. Shlyagina, S.N. Enikolopov, Methods of preparation for intercultural interaction (Izd-vo Mosk. un-ta, Moscow, 1993)

17. H.C. Triandis, Culture and social behavior (Forum, Moscow, 2007)

18. C. Kagitcibasi, Y. Kisbu-Sakarya, E. Aydogdu, International Journal of Intercultural Relations 61 21-28, (2017)

19. M. Yarosh, D. Lukic, R. Santibáñez-Gruber, International Journal of Intercultural Relations 66, 52-72 (2018)

20. J. Seth, International Journal of Intercultural Relations 74, 1-6 (2020)

21. N.A. Orekhovskaya, A.A. Galushkin, E.V. Maleko, T.A. Bezenkova, N.A. Plugina, XLinguae 11(2), 256-264 (2018)

22. N.A Orekhovskaya, E.I. Zamaraeva, E.V. Shikh, R.I. Platonova, A.M. Ishmuradova, XLinguae 12(4), 155-164 (2019) 